\title{
DETERMINAÇĀO COMPLEXOMÉTRICA DE CÁLCIO E MAGNÉSIO EM CALCÁRIO
}

Elene Marisa Pippi

Departamento de Química. Centro de Ciências Naturais e Exatas.UFSM. Santa Maria, RS.

RESUMO

Neste estudo propõe-se um método analītico que permite a determinação simultânea de cālcio e magnēsio em calcārio. Estes me tais alcalino terrosos formam complexos muito estáveis com o sal só dico do ácido etilenodiaminotetraacētico ( $\left.\mathrm{Na}_{2}-\mathrm{EDTA}\right)$. Uma vez contro lado o pH verifica-se a seletividade na complexação. Usa-se como in dicador da titulação do magnésio, o negro de eriocromo $T$ e para a titulação do cālcio, o calcon.

SUMMARY

PIPPI,E.M., 1982. Complexometric ti.trations of calcium and magnesium in limestone. Ciência e Natura (4):67-70.

The calcium and magnesium amounts are determined in limes tones. This alkaline earths are stable complexes, with sodium salt of the ethylenediamintetraacetic acid. If the $\mathrm{pH}$ is controled, there is seletivity in the complexation and separation of such elements. The indicators used are the black eriochrom $T$ for magnesium, and the calcon for calcium.

\section{INTRODUÇÃO}

A anālise complexomētrica iniciou em 1945, quando SCHWAR ZENBACH (3) descreveu o fundamento dos mētodos analíticos baseados na complexação de metais, por compostos poliaminocarboxîlicos. A com plexometria é largamentè empregada em quỉmica analítica quantitatị va em substituição aos mētodos volumētricos clàssicos.

A determinação quantitativa de cālcio e magnēsio requer um mētodo que permita a determinação individual de cada um destes me tais sem que haja interferência de um na determinação de outro, o que torna o trabalho do analista bem mais complexo.

GUENTHER (1) propõe a tēcnica de determinação de cālcio e magnésio por complexometria usarido o $\mathrm{Na}_{2}$-EDTA e como indicadores, 0 negro de ericromo $T \in$ o calcon. Neste trabalho, propõe-se a aplica ção deste mētodo com algumas modificações para a determinação de cāl cio e magnēsio em calcārio, simultaneamente, sem operações prēvias de separação, em soluções tamponadas no pH 10 e 12, respectivamente. Para esta finalidade usa-se tampões de hidrōxido de amōnio-clore to de ámônio. 
Foram utilizadas amostras de calcārio procedentes de Caça pava do Sul, RS. As amostras foram coletadas a uma profundidade mé dia de $5 \mathrm{~m}$ e em distância horizontal não superior a $6 \mathrm{~m}$.

0 método proposto por GUENTHER (1) é o seguinte:

Secar a amostra a $110^{\circ} \mathrm{C}$ e pesar cerca de $0,8 \mathrm{~g}$ de dolomito; aquecer com $10 \mathrm{ml}$ de HCl IM para dissolver a amostra e ferver para remover o excesso de $\mathrm{CO}_{2}$. Ignorar a sîlica, mas fazer o teste para a comple ta dissolução, adicionando $1 \mathrm{ml}$ a mais de $\mathrm{HCl}$ durante o aquecimento, apōs haver cessado a efervescēncia. Esfriar e diluir quantitativamen te num frasco volumētrico de $250 \mathrm{ml}$.

Cálcio + Magnésio total: pipetar $25 \mathrm{ml}$ da solução, juntar igual volume de āgua e cerca de $100 \mathrm{mg}$ de ācido ascōrbico; agite du rante 1 minuto e juntar $1 \mathrm{ml}$ de $\mathrm{NaOH} 6 \mathrm{M}$, com cerca de $50 \mathrm{mg}$ de $\mathrm{KCN}$; aquecer a $40^{\circ}-50^{\circ} \mathrm{C}$ e esperar redissolver qualquer precipitado. Jun $\operatorname{tar} 5 \mathrm{ml}$ de tampão pH 10, 3 gotas de indicador (calmagita ou erio T) e titular, enquanto estiver aquecendo, com EDTA padrão 0,22M até ní tida coloração azul. Calcular a soma do número de Ca + Mg presentes.

cázcio: repetir o procedimento utilizado na primeira par te com alíquotas recentes de $25 \mathrm{ml}$, substituindo $4 \mathrm{ml}$ de $\mathrm{NaOH}$ (sem tam pão) e com indicador calcon. Neste pH (12 e 13) precipita o hidróxi do de magnésio que não é titulado. Deve-se aproximar do ponto final lentamente, para que o carbonato de cālcio que possa ter se formado redissolva-se e reaja. 0 ácido ascörbico e o KCN são usados somente na primeira parte. Calcular o nūmero de nmol de $\mathrm{Ca}^{2+}$ e $\mathrm{Mg}^{2+}$ e a por centagem de carbonato de cālcio e de magnēsio da amostra original.

0 método aplicado neste trabalho, baseado nos princípios do mētodo de GUENTHER (1), com modificações ē o seguinte:

Secar o calcärio triturado a $110^{\circ} \mathrm{C}$ durante 1 hora; pesar cerca de $0,7 \mathrm{~g}$ de amostra. Dissolver a amostra com $20 \mathrm{ml}$ de $\mathrm{HCl}$ (1:10) e ferver; filtrar para retirar a sîlica insolúvel e diluir quantita tivamente a $250 \mathrm{ml}$.

Pipetar $25 \mathrm{ml}$ de amostra, igual volume de āgua destilada e agitar. Acrescentar $1 \mathrm{ml}$ de $\mathrm{NaOH} 6 \mathrm{M}$. Aquecer entre $40-50^{\circ} \mathrm{C}$ atē dis solver o precipitado inicialmente formado. Juntar $5 \mathrm{ml}$ do tampão $\mathrm{pH}$ 10 e $5 \mathrm{mg}$ de negro de eriocromo T. Titular a quente, com $\mathrm{Na}_{2}-$ EDTA $^{-}$ $0,22 M$ atē nîtida coloração azul. 0 nümero de ml gastos nesta titula ção corresponde ao total de cālcio e magnésio na amostra.

Determinação de cálcio: aos $25 \mathrm{ml}$ de amostra adicionar $4 \mathrm{ml}$ de $\mathrm{NaOH} 6 \mathrm{M}$ e $5 \mathrm{mg}$ de calcon. Observar o pH que deverá estar entre 12 e 13. Titular lentamente com Na ${ }_{2}$ EDTA $0,22 \mathrm{M}$ atē coloração azul. 0 nū mero de ml gastos nesta titulação corresponde ao cālcio contido na amostra. Por diferença, entre a titulação da primeira parte e da se 
gunda parte, tēm-se a correspondēncia para o magnēsio.

\section{RESULTADOS E DISCUSSÃO}

Os dados expostos na Tabela I correspondem aos valores mé dios de no mínimo 4 aberturas de cada amostra. Os resultados apresen tados para cada amostra é a média encontrada por 4 titulações.

TABELA I. RESULTADOS OBTIDOS NAS DETERMINAÇOES DE CĀLCIO E MAGNESIO EM AMOSTRA DE CALCARIO ANALISADAS.

\begin{tabular}{ccc}
\hline \hline AMOSTRA NO & CALCI0 & MAGNESI0 \\
\hline 1 & 23,92 & 5,30 \\
2 & 23,92 & 5,30 \\
3 & 23,90 & 5,40 \\
4 & 23,29 & 5,36 \\
5 & 23,92 & 5,30 \\
6 & 22,67 & 5,34 \\
7 & 23,92 & 5,30 \\
\hline MEDIA & 23,64 & 5,34 \\
\hline
\end{tabular}

$S(\Delta)$ para o cālcio $= \pm 0,45 \quad S(\Delta)$ para o magnésio $= \pm 0,036$

A determinação complexomētrica de cālcio em presença de magnēsio tem na prātica uma grande importāncia. Segundo MERCK (2) é conveniente usar indicadores específicos para o cālcio como o calcon ou o ácido calconcarboxīlico. Também é possível utilizar a murexida ou a calceína.

MERCK (2) salienta muito a importāncia das determinações complexométricas de cālcio e magnésio para a anālise da dureza da àgua.

A titulação complexométrica de cālcio e magnēsio atravēs do método proposto, apresenta facilidade de execução e resultados concordantes entre si, desde que sejam rigorosamente observadas as condições da tēcnica. A exatidão e a precisão de resultados se in terligam mais diretamente com o controle adequado do $\mathrm{pH}$ e da tempe ratura das titulações.

0 aquecimento é necessārio a fim de acelerar a velocidade de reação entre o complexo Mg-eriocromo $\mathrm{T}$ e o $\mathrm{Na}_{2}$ EDTA.

0 complexo Mg-EDTA sō ē estävel em pH 10. 0corre inicial mente a reação Ca-EDTA, pois em pH 12 somente o cálcio reage com e $\mathrm{Na}_{2}$ EDTA e o magnēsio forma hidrōxido de magnēsio, não sendo comple xado nestas condições de $\mathrm{pH}(12$ a 13$)$.

Este controle, portanto, deve ser rigoroso sob pena de pre 
judicar todos os resultados obtidos. Os indicadores foram usados na forma sōlida da substāncia p.a, devido a pequena estabilidade de suas soluções.

CONCLUSOES

A determinação de cālcio e magnēsio em calcārio, atravēs do método proposto, é possivel porque esses elementos formam comple xos estāveis com o sal sōdico do ācido etilenodiaminotetraacético. $\mathrm{Na}$ titulação do magnésio usa-se o negro de eriocromo T e na de cāl cio, o calcon.

\section{REFERENCIAS BIBLIOGRAFICAS}

1. GUENTHER, W.B., Quimica Quantitativa, Medicões e Equilibrios, Edgard Blucher Ltda, São Paulo, 1972, pp. 384.

2. MERCK, E., Métodos complexométricos de titulacão com titriplex, Darmstadt, Alemanha, 2. ed, 1964, pp. 21,33,34,47.

3. SCHWARZENBACH, G., Analytica Chem. Acta., 7,141 (1952).

Recebido em dezembro, 1982; aceito em dezembro, 1982. 